\title{
DR. 757
}

LA-8185-MS

Informal Report

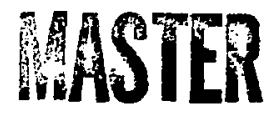

Comparison of Zero-Dimensional and One-Dimensional

Thermonuclear Burn Computations for the Reversed-Field Pinch Reactor (RFPR) 


\title{
COMPARISON OF ZERO-DIMENSIONAL AND ONE-DIMENSIONAL THERYONUCLEAR BURN COMPUTATIONS FOR THE REVERSED-FIELD PINCH REACTOR (RPPR)
}

\author{
by
}

R. A. Nebel, R. L. Hagenson, R. W. Moses, and R. A. Krakowski

\begin{abstract}
Conceptual fusion reactor designs of the Reversed-Field P1nch Reactor (RFPR) have been based on profile-averaged zero-dimensional (point) plasma models. The plasma response/performance that has been predicted by the point plasma model is re-examined by a comprehensive one-dimensional (radial) burn code that has been developed and parametrically evaluated for the RFPR. Agreement is good between the zero-dimensional and one-dimensional models, giving more confidence in the RFPR design point reported previously from the zero-dimensional aualysis.
\end{abstract}

\section{INTRODUCTION}

A comprehensive conceptual design of a fusion power reactor based on the Reversed-Field P1nch (RFP) has recently been published. I The plasma physics model used to estimate the thermonuclear burn dynamics and fusion yield was based on a zero-dimensional or "point-properties" formulation. This "point" model effectively averaged all cruclal plasma properties (i.e., fleld, density, and temperature profiles) In accordance with the Bessel-function model $^{2,3}$ for magnetic field profiles. 
A part of a continuing paranetric analygis and refinement of the RFPR concept, a more reallstic one-dimensional (radial) plasma model has been developed ${ }^{4}$ and applied to the point design reported in Ref. 1. The results of this comparison and possible alterations in future RFPR design points are reported herein. Before reporting the results of these parametric analyses, however, background 1tems that are pertinent to the RFP are reviewed.

\section{BACKGROUND}

\section{A. Physics of the RFP}

Like the tokamak, the RPP is a toroldal, axisymmetric confinement device. Both systems use a combination of pololdal, $B_{\theta}$, and toroddal, $B_{\phi}$, magnetic flelds to confine a plasma in a minimum energy state. For both systems the pololdal field is created by inducing through transformer action a large toroldal current, $I_{\phi}$, within the plasma column; the $B_{\phi}$ field results from current flowing in external colls. Figure 1 schematically depicts the field and pressure profiles across the plasma minor radius for both tokamak and RFP systems. Toroldal equilibrium in both systems can be achleved by elther using a conducting shell near the plasma, an external vertical field, or a combination of both schemes. The RFP requires a conducting shell for plasma stabilization against unstable MHD modes with wavelengths in excess of the shell radius, $r_{w}$, whereas the tokamak is not necessarily subjected to this requirement. Localized MHD modes in the RPP are suppressed by the strongly sheared magnetic fields caused by a slight reversal of the $B_{\phi}$ fleld at the plasma edge (Fig. 1). Although the tokamak does not require a conducting shell near the plasma column, stabilization of the kink Instability establishes specific requirements on the relative magnitude of $B_{\theta}$, $B_{\phi}$, the plasma radius, $r_{p}$, and the major radius of the torus, $R$. Specifically, for the tokawak the safety factor, $q=\left(r_{p} / R\right)\left(B_{\phi} / B_{\theta}\right)$, must be greater than unity, which assures that MHD kink modes with wavelengths in excess of the major circunference wil be stable. Experimental values of $q \sim 2-3$ are required for stable plasma operation. The RFP, on the other hand, operates with $q$ less than unity; the q-value actually falls through zero and becomes negative outside the plasma region, $r>r_{p}$. The presence of a passive conducting shell In the RFP replaces the $q>1$ stability criterion with one that requires $(d q / d r) \neq 0$; the variation of the plasma/field shear should not exhibit a inimim In the region enclosed by the conducting shell. The reactor 


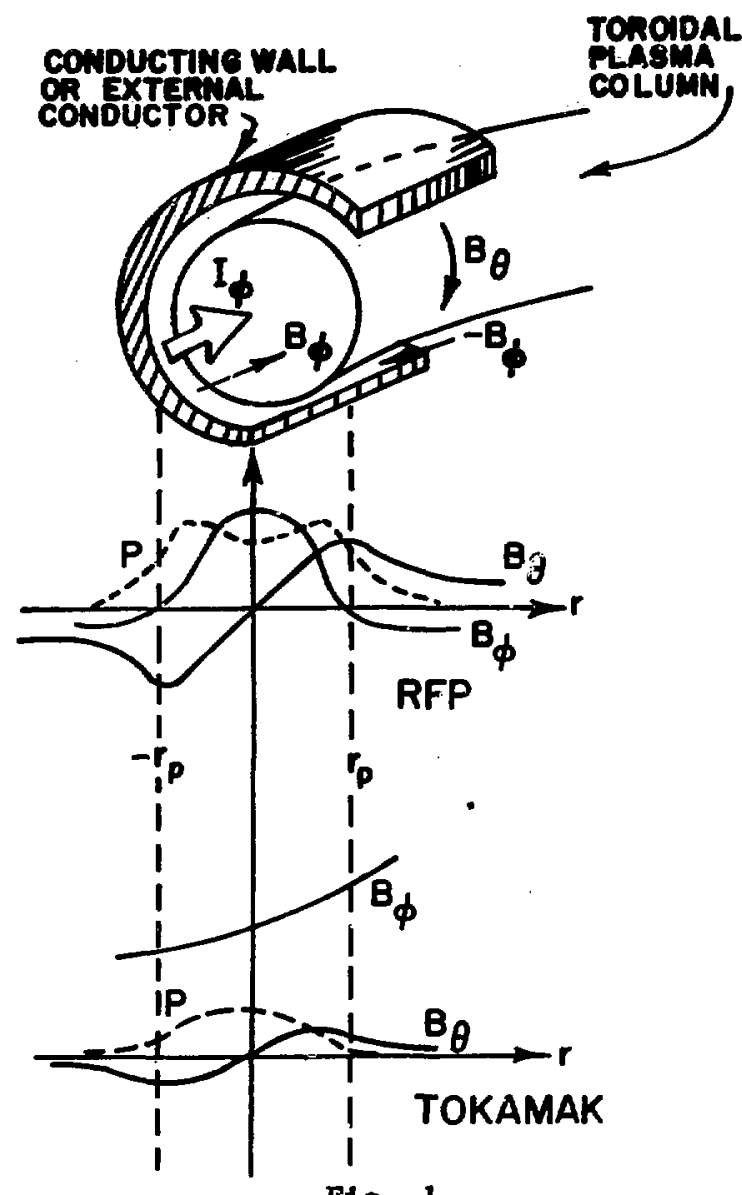

Comparison of magnetic and pressure profiles for a $\mathrm{dq} / \mathrm{dr} \neq 0$ stabilized RFP and $a \mathrm{q}>1$ stabilized tokamak.

disadvantages assoclated with (passive) wall stabilization or (active) coll stabilization are countered by the advantages the RFP approach exhibits when not constrained by the $q>1$ criterion. Imposition of the $q>1$ constraint Implies small values of $R / r_{p}$ and $B_{\theta} / B_{\phi}$, which in turn create the following problems for tokamaks:

- Since the plasma pressure is essentially held by the $B_{\theta}$ fleld, the ratio of plasma pressure to total fleld pressure is small, implying a poor utilization of magnetic field energy per unit of fusion yield.

- Since $B \theta / B_{\phi}$ is limited and since practical coll desfign establishes physical limits on the toroldal field, $B \phi$, the plasma current, $I_{\phi}$, is limited. This limit imposed on $I_{\phi}$ generally precludes significant ohmic heating, thereby necessitating more compiex and less efficient plasma heating schenes (1.e., neutral atom beams, radio-frequency heating). 
- The $q>1$ constraint also enforces 1 inits on the plasma aspect ratio, $R / r_{p}$. In addition to obvious engineering and system problems that accompany the design of low-aspect ratio reactor tori, relatively large inhomogenelties result in the toroldal field, $B_{\phi}$, that in turn lead to numerous trapped-particle Instabilities and enhanced transport of particles and/or energy from the plasma. Low aspect rat1os also lead to a less efficlent coupling of the pololdal fleld energy to the plasma.

- Generally, the $q>1$ constraint forces the utilization of the highest possible toroidal flelds, $B_{\phi}$, and, therefore, causes a difficult magnet design task and the storage of considerable quantities of magnetic energy per unit of contained plasma energy.

In a sense, therefore, the RFP approach "differentiates away" the $q>1$ constraint Imposed on tokamaks and In 1 ts place requires $(\mathrm{dq} / \mathrm{dr}) \neq 0$. The positive Implications of this alternative stability criterion are:

- The aspect ratio, $R / r_{p}$, can be chosen solely on the basis of engineering considerations and conventence:

- The $\beta$ IImits predicted for the RFP are at least 10 to 50 times greater for $q>1$ sjgtems if Ideal MHD theories are used. The use of resistive theorles reduce this factor from 10-50 to 3-10, which still represents a significant Improvement.

- The plasma may be brought to ignition with ohmic heating alone with the poloidal field system, which is also in place to confine the plasma pressure.

- The confinement of high-to-moderate $B$ plasma is achleved primarily by pololdal flelds, $B_{\theta}$, which characteristically decrease with increased distance from the plasma, thereby considerably reducing fields and stresses at the magnets.

- The use of field reversal near tiae plasma edge for the $\mathrm{dq} / \mathrm{dr}<0 \mathrm{RFP}$ configuration makes possible a "vacuum" (low current) region to be established between the plasma and first wall.

Although Implicationg of these Improvements are significant from the reactor viewpoint, they are accompanied by the perceived need for a passively conducting first wall. Additionally, the energy that must be expended in establishing and maintaining the near pinimum-energy RFP configuration is not known, but if this setup/sustenance energy is significant, operation as an Ignition device is made more difficult. Lastly, little or no consideration has been given to the physics Implications of fueling and ash-removal systems required for a steady-atate operation; the RFPR design presented in Ref. 1 is based on a long-pulsed (25-30 s) batch-burn operation. The favorable energy 
balance (rectrculating power fraction 180.17 ) computed for the batch-burn mode of operation reflects the efficient use of magnetic field energy by the RFP, although technological 18sues associated with pulsed superconducting magnets and energy transfer/storage systems w11 require further development and study.

The plasma 1ssues of stability and field reversal, as they impact on the RFPR model, have been reviewed in Ref. 1. Stable field profiles within the plasma, an example of which is 11lustrated in $\mathrm{Fig}$. 2, are modeled by Bessel functions. These profiles are integrated over the plsma radius to give the time-dependent, point model. Generally, ideal MHD stable profiles have been found using numerical methods if the followirg three constraints are imposed: - net positive toroldal flux: $\int_{0}^{r} w_{B} 2 \pi r d r>0$

- pololdal $B$ limit: $\beta_{\theta}<0.5+{ }_{B}^{0}\left(B_{\phi}=0\right)$

- Suydam criterion: $r\left[(d \ln v / d r]^{2}+[d p / d r] 8 \mu_{0} / B_{\phi}^{2}>0\right.$,

where $r_{w}$ is the radius of the conducting shell, $B_{\theta}\left(B_{\phi}=0\right)$ is the local $\beta$ at the zero point of the toroidal fleld, $p$ is the plasma pressure, and $d \ln v / d r$ is



Fig. 2. .

Compartson of stable RFP profiles computed numerically with the Bessel function profiles used to generate the point RFPR plasma model. 
the magnetic field shear, with $v=B_{\theta} / \mathrm{rB}_{\phi}=1 / \mathrm{qR}$. The first two conditions have been Imposed on all RFPR burn simulations, whereas the third condition cannot be Imposed directly on the point model used; the Bessel function proflles ( $\left./ \mathrm{H}_{\mathrm{g}} \cdot 2\right)$, however, are generally a very good approximation to profiles that satiafy the Suydam criterion. A major objective of the one-dimensional calculation presented hereln is to examine this latter 1ssue.

The question of toroldal fleld reversal has also been addressed in Ref. 1 and probably represents the single greatest physics uncertainty for the RFPR. The reactor computations sssume that fleld reversal occurs spontaneously and Is maintained automatically throughout the burn period by an unspecified relaxation process or instabllity. Self-reversal of the toroidal field is an experimental fact, but the assoclated energy 1088 ls not known. The energy 108 assoclated with this sustained self-reversal, therefore, was assumed equal to loss rates measur ${ }^{\circ}$ from large tokamak experiments, which indicate that the energy confinement times equal approximately 200 Bohm diffusion times. That self-reversal occurs is not in question; the self-reversed pinch state has been observed in many RFP experiments over the last 25 years. Recent theorles ${ }^{2,3}$ of relaxed states have led to a substantial Increase in fundamental understanding of this minimum-energy, field-reversed state. Given any arbitrary dissipation mechanism, these theories predict that a plasma surrounded by a flux conserving shell will relax to a minimum-energy, force-free, zero-B state. This minimum-energy state is described by the Bessel function model given $\mathrm{In} \mathrm{FIg}$. 2. Numerical methods have confirmed this behavior for $h i g h-\beta$, reversed-field plasmas. The key descriptive parameters in the Taylor theory ${ }^{2}$ are the pinch parameter, $\theta$, and the reversal parameter, F, where

$$
\begin{aligned}
& \theta=B_{\theta}\left(r_{w}\right) /\left\langle B_{\phi}\right\rangle \\
& F=B_{\phi}\left(r_{w}\right) /\left\langle B_{\phi}\right\rangle \\
& \left\langle B_{\phi}\right\rangle=\left(2 / r_{w}^{2}\right) \int_{0}^{r_{w}} B_{\phi} r d r .
\end{aligned}
$$


Figure 3 shows the locus of minimum energy states as described on the $F-\theta$ dlagram; both the analytic $(\beta=0)$ Taylor state ${ }^{2}$ and the numerical high- $\beta$ states are shown. The destred fleld-reversed state corresponds to $F<0$ and $1.2<\theta<1.6$. It is noted that high- $B$ RFP states have been observed both experimentally and numerically for higher $\theta$ values, but the Taylor theory predicts an ultimate relaxation to the minimum energy states given on Fig. 3; both relaxation mechanism and assoclated time constants for this sustained, self-reversal of toroldal field are not well understood at this time. It is noted that the minimum-energy tokamak state is described hy the Taylor theory as the point where $F=1$, for which $\theta \simeq \mathbf{r}_{p} / R$. The penalties incurred for operation near this state, however, have been previously discussed.

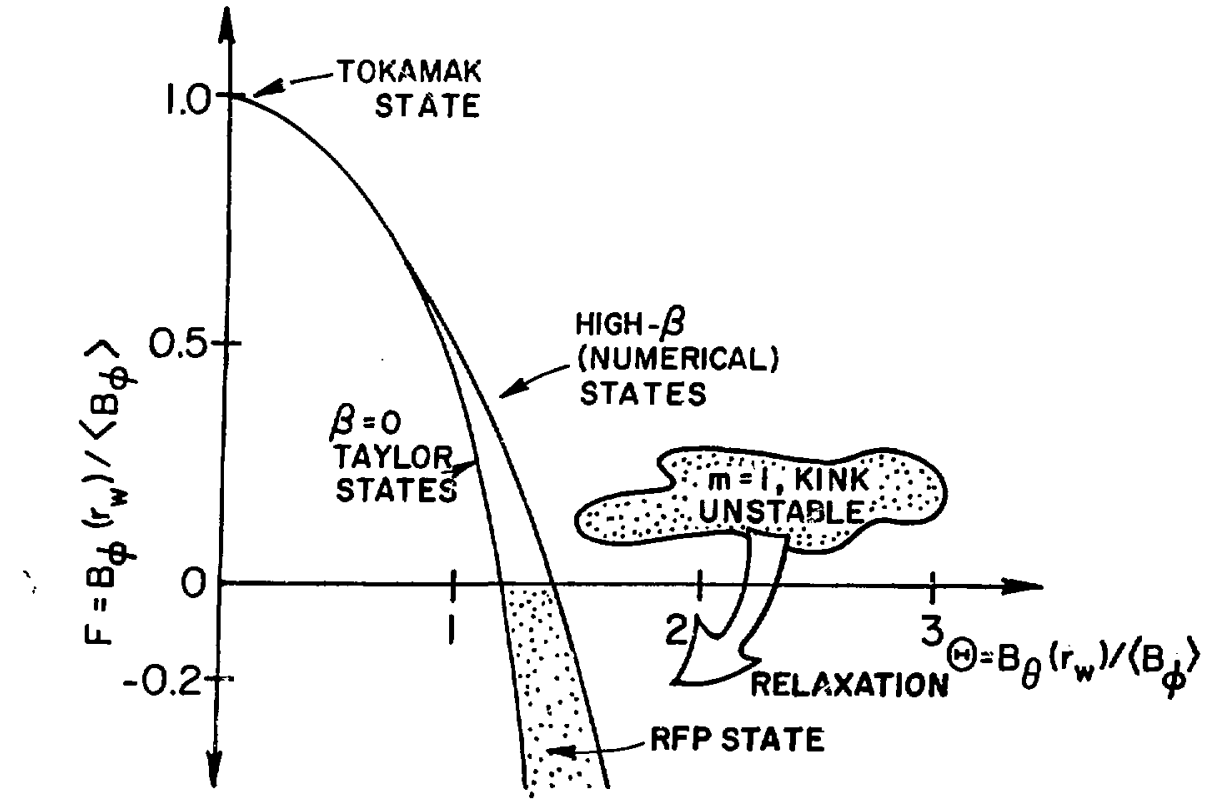

F1g 3.

Region of stable, minimum-energy states displayed on F - $\theta$ diagram for both low- $B$ (Taylor) and high- $\beta$ (numertcal) RFP plasmas. 


\section{B. Description of RFPR Based on Polnt Plasma Model}

To the casual observer a magnetically confined fusion reactor appears as an Intertwined array of coolant ducts penetrating an almost Inaccessible toroldal assembly of superconducting magnets. If, however, the toroidal aspect ratio can be made sufficlently large to approximate a 1Inear geometry and to allow the use of nearly cylindrical blanket modules, this problem of accessibility can be considerably reduced. Furthermore, if the primary plasma confinement system can be combined with the major plasma heating scheme, large and complex appendages can be ellminated from the torus, and the reactor system becomes even less complicated. Finally, If the appreclable plasma pressures (30-60 MPa) can be supported primartly by pololdal magnetic fields, which characteristically decrease in strength as the minor radius Increases, the low-fleld superconducting coils can be removed from the vicinity of the blanket/shleld without a serlous Increase In stored magnetic energy; the accessibility problem is thereby further reduced. The RFP combines all three of these requirements; arbitrary aspect ratio, combined heating and confinement system, and low-fleld magnets. These features, additionally, exist for a scheme whose physics admits the potential for a regenerative, near minimum-energy, high- $\beta$ plasma state. These physics characteristics directly and favorably Impact the reactor design that has been presented In Ref. 1 . Potential problem areas for the RFPR include the presently perceived need for a 20-mm-thick copper first wall for short-time ( 0.1 s) plasma stabilization and the need for pulsed ( 0.1-8 risetime, 25-30 s dwell time) magnetic energy transfer and storage.

The time-dependent burn model, plasma and englneering energy balances, and the stability/equilibrium criteria upon which this RFPR design is based are described In Ref. 1 and summartzed In Table I. Table II glves a summary description of key reactor parameters.

Upon Induction of the $20-\mathrm{MA}\left(5.4 \mathrm{MA} / \mathrm{m}^{2}\right)$ toroldal current in $\sim 0.1 \mathrm{~s}$, the plasma ohmically heats to ignition in $\sim 3 \mathrm{~s}$, as shown by the results of the RFPR point burn toodel In Fig - 4. The plasma subsequently burns for $15 \mathrm{~s}$ at $20 \mathrm{keV}$ to yield a fuel burnup fraction, $f_{B}$, of 0.5 . The end of the burn is determined by the Ion temperature dropping below $8 \mathrm{keV}$, as the plasma $10 s \mathrm{ses}$ begin to exceed the alpha-particle heating. At this point the plasma is expanded to the wall by opening switches in both poloidal and toroldal coll systems. Current in the pololdal field coll to again reversed by using a 


\section{TABLE I}

RFPR REACTOR (POINT PLASMA) PHYSICS MODEL

- Pressure-balance model using average properties

$$
\begin{aligned}
& B_{\theta}=A_{\theta} J_{1}(\alpha r) \\
& B_{\phi}=A_{\phi} J_{0}(\alpha r)
\end{aligned}
$$

- Three specles

- Maxwellian Ions and electrons

- Fokker-Planck alpha particles

- Ohmic heating using modified classical resistivity

- Bremsstrahlung, cyclotron, Iine radiations

- Tokamak start-up code (separate)

- Anomalous (Bohm) radial transport

$$
\text { Typically, } \tau_{E}=200 \tau_{B O H M}
$$

- Time-dependent properties (temperatures, densities, radius)

- Circuit model option

- First-wa11 heat transport and stress response

- Detafled reactor energy balance

- Direct interface with comprehensive costing model

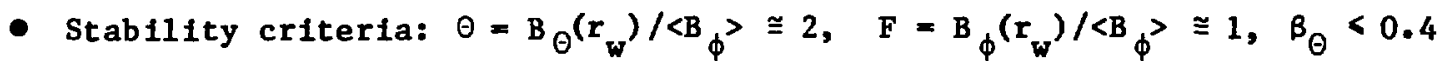

homopolar motor/generator set as a transfer element, this action resulting in a current flowing in the coil between burn pulses. The toroidal field energy left untrapped within the plasma is extracted from the reactor and stored in the homopolar between burn pulses. Magnetic field trapped in the plasma at the termination of the burn is assumed to be thermally dissipated and delivered as heat to the blanket through the first wall. Neutral DT gas is added at this point to promote a controlled plasma quench and dilution of the alpha-particle ash. Continuous pumping by the vacuum system readies the plasma chamber for the next burn pulse during the 5-s dwell period. Table III gives a summary energy balance for the burn cycle depicted in Fig. 4.

Throughout the burn cycle, including the startup and approach to ignition, the energy confinement time was fixed at 200 times the instantaneous Bohm diffusion time, this scaling being deduced ${ }^{1,5}$ from existing tokanak experimental data. Both in magnituie and in terms of functional scaling, this loss rate is sufficient to control the plasma $B$ and leads to a stable burn 
TABLE II

SUMMARY DESCRIPTION OF RFPR DESIGN PARAMETERS

PARAMETER

First-wa11 radius, $r_{w}(m)$

Major radius, R(m)

Toroidal plasma current, $I_{\phi}(M A)$

Toroidal field at the coil, $B_{\phi c}(T)$

Pololdal field at the coil, $\mathrm{B}_{\theta_{c}}(\mathrm{~T})$

Toroidal coll energy, $W_{B \phi}(G J)$

Poloidal coll energy, $W_{B}{ }^{(G J)}$

Field rise time, $\tau_{R}(s)$

Burn time, $\tau_{B}(s)$

Cycle time, $\tau_{C}(s)$

Average fuel burnup, $f_{B}$

Average plasma density, $\mathrm{n}\left(10^{20} / \mathrm{m}^{3}\right)$

Average plasma temperature, $T_{1, e}(\mathrm{keV})$

14.1-MeV neutron current at first wall, $I_{W}\left(\mathrm{MW} / \mathrm{m}^{2}\right)$

Engineering Q-value, $Q_{E}$

Recirculating power fraction, $E=1 / Q_{E}$

Average blanket power density, $\mathrm{P}_{\mathrm{BLK}}\left(\mathrm{MW} / \mathrm{m}^{3}\right)$

Average system power density, $P_{S Y S}\left(M W / m^{3}\right)$

Total thermal power, $\mathbb{P}_{\mathrm{TH}}$ (MWt)

Net electrical power, $P_{E}$ (MWe)

Net plant efficiency, $\eta_{p}=\eta_{T H}(1-\varepsilon)$
VALUE

1.5

12.7

20.0

2.0

2.0

3.7

11.0

0.1

21.6

26.6

0.5

2.0

15

2.7

5.8

0.17

4.7

0.9

3000

750

0.25

trajectory. Simultaneously, the burn trajectory in F - $\theta$ space, as seen from Fig. 4, follows closely the predictions of the iaylor uinimum-energy model. The physics operating point summarized In Fig. 4 and Tables II and III represents the culmination of an extensive parameter search which used as an object function the plant capital and power costs. I This point-plasma design point is re-examined here in terms of a one-dimensional burn code. 


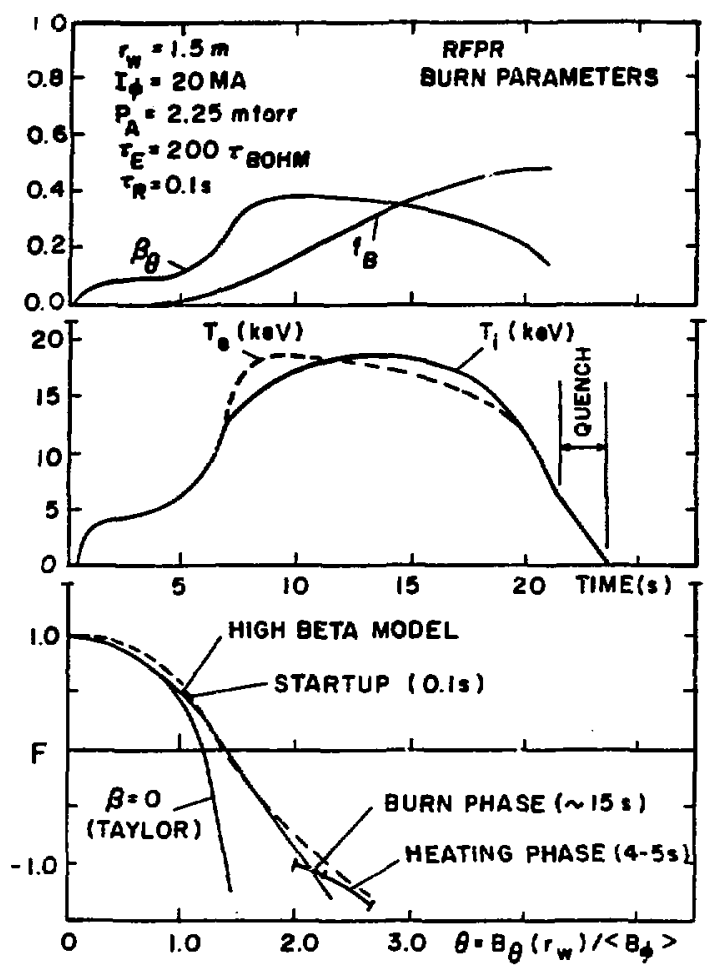

F1g * 4 .

RFPR (superconducting coils, air-core system) burn parameters using an energy confinement time $\tau_{F}=200^{\circ} \tau_{B O H}$. The burn trajectory is in good agreement with that required by the high- $\beta$ model for a minimum-energy configuration (Fig. 3).

III. ONE-DIMENSIONAL RFPR THERMONUCLEAR BURN

Like the point model previously described, the one-dimensional model treats a three-particle quasi-neutral gas of electrons, DT-ions and alpha particles. The embedded magnetic field has a toroidal and a poloidai component, $B_{\phi}$ and $B_{\theta}$, respectively. Radial field diffusion and plasma convection in this azimuthally symmetric system are modeled under a magnetohydrostatic approximation, and thermal conduction for Ions and electrons are computed separately. The plasma is heated ohmically, and radiation losses Include bremsstrahlung and electron cyclotron channels. A Fokker-Planck model is used to partitlon the alpha-particle energy appropriately between DT lons and electrons. A number of approximations were used to describe the spatial distribution of both energy deposition and mass accumulation for the alpha particles. 
TABLE III

SUMMARY ENERGY BALANCE FOR A 21.6-8 BURN AND A 26.6-8 CTCLE TIME

\section{PARAMETER}

Inttial plasma energy

Final plasiá energy

Resiation energy ${ }^{a}$

Ohmic heating energy

Plasma energy $108 s$ (conduction) $^{b}$

Plasma expansion energy

Eddy current losses in the blanket/shield

Magnetic-field energy lost at end of burn cycle $e^{c}$

Magnetic-fleld energy transfer losses $d$

Fusion neutron energy

Aurlilary energy requirements
VALUE (MJ/D)

0.05

2.5

28.1

7.1

147.5

0.7

1.5

21.5

8.1

792.

14.3

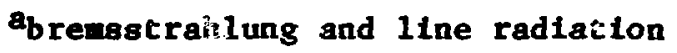

$b_{\text {based }}$ on an energy confirement time equal to 200 Bohn diffusion times

cassimed to be thermally dissipatad

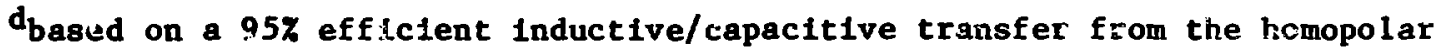
motor/generator (capacj.tive) to and from the nagnets


the aurillary power

\section{A. Radiel Transport}

The radial burn code uses an 1mplicit Lagranglan meshing technique that has been developed explicitly for modelling plasma processes on a time scale that is long In comparison to the sound transit time; Inertial terms in the MHD equations are, therefor s, 1gnored, and plasma motion is thereby determined by a quasi-static pressure balance, $\vec{J} \times \vec{B}=\vec{\nabla}_{p}$. This approximation infers that the quasi-static equilibrium profiles are stable, and this assumption is exanined perlodically by a separate algorithm. The pressure balance constraint 18 expressed by the following integral equation for systems that exhibit both axial and azimuthal invariance.

$$
p+B^{2} / 2 \mu_{0}=\left(2 / r^{2}\right) \int_{0}^{r}\left(p+B 2 / 2 \mu_{0}\right) r^{\prime} d r^{\circ}
$$


where $P$ is the total plasma pressure, $B^{2}=B_{\phi}^{2}+B_{\theta}^{2}$ and aks units are consistently used except for the temperature, $T(\mathrm{keV})$.

Plasma parameters are computed as functions of time by a two-step nethod. Ftrst, the Lagrangian mesh 18 fixed in space for the computation of all diffusion, radiation, and heating processes. Secondly, the Lagranglan mesh is adjusted In space to satisfy the pressure balance constraint given by $\mathrm{Eq}$. (7)..

The first phase of this two-step process, wherein all transport is computed, 18 described by the following expressions for lon density $n_{1}$, alpha-particle deneity $n_{\alpha}$, energy of the $j$ th species $T_{j}(j=e, 1, \alpha)$, and magnetic fleld.

$$
\begin{aligned}
& \frac{\partial n_{1}}{\partial t}+\vec{\nabla} \cdot \vec{r}_{1}=s_{1}-2 f(1-f)<\sigma v>n_{1} \\
& \frac{\partial n_{\alpha}}{\partial t}+\vec{\nabla} \cdot \Gamma_{\alpha}=f(1-f)<\sigma v>n_{1}^{2} f_{\alpha} \\
& \frac{3}{2} n_{j}(10)^{3} e \frac{\partial T_{j}}{\partial t}+p_{j} \vec{\nabla} \cdot \overrightarrow{r_{j}}=-\vec{\nabla} \cdot q_{j}+Q_{j} \\
& \frac{\partial \vec{B}}{\partial t}=\vec{\nabla} \times\left[-\vec{v} \times \vec{B}+\frac{1}{e_{e}} \vec{R}_{T H}+n_{\|}{ }_{N} \vec{e}_{\|}+n_{\perp} J_{\perp} \vec{e}_{\perp}\right]
\end{aligned}
$$

The fluid velocity with respect to the Eulerian coordinates is $\vec{v}, \vec{r}_{j}=n_{j} \vec{v}_{j} 18$ the particle flux, $S_{j}$ is an Ion source term, f 18 the tritium fraction, $f_{\alpha}$ is an alpha-particle confinement effictency, $q_{j}$ is a thermal hest $f 1 u x, Q_{j}$ is a heat source, and $\vec{R}_{\mathrm{TH}}$ represents a thermal force. The parallel and perpendicular resistivities, $n_{\|}$and $n_{1}$, are treated either classically or with anomalous effects, and $e\left(1.602(10)^{-19} \mathrm{~J} / \mathrm{eV}\right)$ is the electronic charge. 


\section{B. Preserure Balance}

Upon evaluating the transport (Eqs. (8)) for a given tiwe step at each radial position, the new values of temperature, density and fields will not eaclefy pressure balance (Eq. (7)). The Lagranglan mesh 18 adjusted adlabatically as a $\gamma=5 / 3$ ideal gas with the new radial positions belng selected to satisfy the Lagranglan constraint. This procedure 18 exiacuted In conjunction with an appropriate boundary condition, such as maintaining a given plasma radius or current. An approprlate energy balance end variable time step 1s used to assure a rapldiy-executing and accurate model.

\section{Stab1lity Nodel}

Two methods are used to monitor the RFP stability in the context of the one-dimensional model. Local modes are assumed to saturate and are monitored using a Suydam criterion. 6 A Rayle1gh-Ritz type energy principle is used to monitor global modes. Both methods for monltorlng stability are derived from the Ideal MHD equations using a cylindrical approximation.

If the plasma is assumed to extend radally, the one-dimensional energy princtple asgures the following form ${ }^{7}$

$$
\delta W=(\pi / 2) \int_{0}^{r_{p}}\left[f(d \xi / d r)^{2}+g \xi^{2}\right] d r,
$$

where,

$$
\begin{aligned}
& f=\frac{r\left(k r B_{\phi}+m B_{\theta}\right)^{2}}{\mu_{0}\left[(k r)^{2}+m^{2}\right]}
\end{aligned}
$$

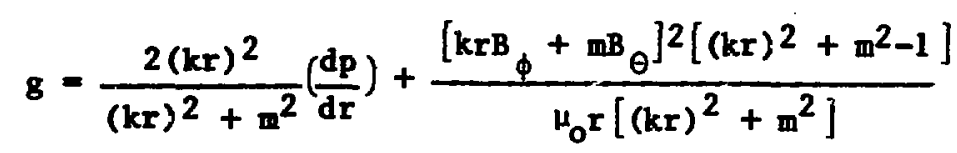

$$
\begin{aligned}
& +\frac{\left.2(k x)^{2}\left[(k r)^{2} B\right\}-m^{2} B \xi\right]}{\mu_{0} r\left[(k r)^{2}+m^{2}\right]^{2}}
\end{aligned}
$$


The axial wave number is $k$, the node number is $m$ and $\xi$ is the radial displacement. In order to avoid the singularity in $\xi$ when $f$ approaches zero the transform $\psi=\xi \sqrt{f}$ proves useful. 8 gquation (9) transforms to

$$
\begin{aligned}
\delta W= & (\pi / 2) \int_{0}^{r} p\left((d \psi / d r)^{2}-(\psi / f)(d f / d r)(d \psi / d r)+\right. \\
& {\left.\left[(d f / d r)^{2} / 4 f^{2}+g / f\right] \Psi^{2}\right) d r }
\end{aligned}
$$

The parameter $\Psi$ is then expanded into a Fourler Saries according to

$$
\psi=\sum_{1=0}^{n_{1}} c_{1} \sin \left(\alpha_{1} r\right),
$$

where $\alpha_{1}=(1+1) \pi / r_{p}$. The constant $c_{0} 18$ normallzed to unity, and the remeining constants, $c_{1}(1=1, \ldots, n)$, are computed to minimize the energy ow by requiring that $\partial \delta \mathrm{W} / \partial \mathrm{C}_{1}=0$ for $1=1, \ldots, n$. The resulting set of $n$ Inhomogeneous equations and unknowns 18 inverted and solved for $C_{1}$. If the resulting value of $\delta$ is negative, the assoclated plasma configuration is considered unstable. This ow stability check is applied to the one-dimensional burn computations for $m=0, k+0$ and $m=1$, $-30 / R<k<30 / R$.

The Suydam criterion, as embodied in Eq. (3), is included in the more general energy princlple stated by Eq. (9). These Suydam modes, however, have elgenfunctions that are asymptotically singular at rational surfaces. Since the mesh size used by the one-dimensional computation 18 finite and determined by the previously described transport computation, elgenfunctions that are more localized than the mesh size will not be detected by the global energy-principle analysis. Consequently, the global stability analysis is able to find gross modes that may also occur simultaneously with Suydan modes, which are assumed to saturate while possibly leading to enhanced transport. The global energy-princtple analysis also quantifies the validity of the assumption that Suydam modes are localized in that the modes will be detected If the associated elgenfunctions extend over a "macroscoplc" (1.e., nesh alse) volume of the plasma. 


\section{Anonelous Transport}

As wil be shown, a large region of the plasma is found to be unstable to local Suydan eodes for the plasea conditions selected for the point plasma operating parameters. The resulting instabilities are assumed to realn localized and to be manifested as enhanced transport. Following a similar study, 9 Bohn transport is assuned to describe these regions of Suydam Instability. Specifically, the perpendicular resistivity, $\eta_{\perp}$, was modified relative to the classical value, $n_{L_{c}}$, according to

$$
\eta_{\perp}=\eta_{\perp c}+f_{T} f_{s} C B^{2} D_{B} / n_{e}
$$

where $f_{T}$ is a trfangular function that spreads the region of enhanced tranøport over five adjacent mesh points ( 10 Larmor rad11) around the location of Suydam Instability, the constant $C 18$ taken as $10^{-4}$, and f is given by

$$
\begin{aligned}
& f_{8}=\left\{\begin{array}{l}
0 \quad \text { if } \varepsilon<1 \\
(\varepsilon-1) / \varepsilon \text { if } \varepsilon>1
\end{array}\right. \\
& \varepsilon=-\frac{\mathrm{dp} / \mathrm{dr}}{\left(\mathrm{B}_{\theta}^{2} / 8 \mathrm{r} \mu_{0}\right)(\mathrm{dP} / \mathrm{dr})^{2}} \\
& P=\mathrm{rB}{ }_{\phi} / \mathrm{B}_{\theta}=1 / \nu
\end{aligned}
$$

By means of this algorithm, the increased perpendicular resistivity forces the current to flow more parallel to magnetic field lines, thereby reducing the pressure gradients (1.e., $\vec{J} \times \vec{B}=\vec{\nabla}_{\mathrm{p}}$ ) that initiated the Suydam Instability and increased radial transport of particles and energy. 
IV. RESULTS

In examining dimensional effects on the thermonuclear yield and overall plasma performance, three computational cases were considered:

- Case A: The one-dimensional model was forced to follow exactly the radius trajectory predicter by the zero-dimensional model.

- Case B: The more physically correct assumption of constant radius and moderately programmed toroidal current was examined.

- Case C: With the plasma radius fixed, regions of Suydam Instability were subjected to significantly enhanced transport in order to model a flattening of the temperature profille (e.g., $\mathrm{Bq} \cdot(14))$.

Similar to the point model, the radial energy transport for Cases $A$ and $B$ is set equal to 200 Bohm times. Cases $A-C$ assume that both the alpha-particle energy and mass are deposited locally. A fourth case, Case D, is Identical to Case A, except the alpha particle mass and energy is deposited across the plasma radius according to the ion density profile. Two additional cases have also been considered: Case $E$ fixes the plasna radius and deposits both alpha-particle wass and energy according to the ion density profile, whereas Case $F$ fixes the plasma radius, distributes the alpha-particle energy according to the fusion reaction rate, and distributes the thermalized alpha-particles according to the Ion density profile. Table IV summarizes the essential elements of the six simulation cases described above.

A. Exact Comparison Between Zero- and One-Dimenslonal Models: forced Plasma Radius Trajectory.

In order to match the point model upon which the RFPR design given in Tables II and III 18 based, the plasma was confined to a trajectory $r_{p}(t)$ given by

$$
r_{p}(t)=r_{p}(t=0) / \sqrt{1-s_{\theta}}
$$

where the plasma radius, $r_{p}$, is defined by the toroldal field reversai point, and $B_{\Theta}$ is the maximum pololdal beta. Initial attempts to duplicate the point model by holding the toroidal current, $I_{\phi}$, constant were not as successul as computations that used the forcing function given by $\mathrm{Eq} \cdot(15)$, although the time variation in $I_{\phi}$ when $I_{p}$ is specified amounts to only a few percent. The Initial temperature distribution was assumed uniform, and the initial density 
TABLE IV

SUMAARY OP CONDITIOAS ASSUABD FOR ONE-DIMENSIONAL STMULATIOHS

\begin{tabular}{|c|c|c|c|c|c|}
\hline Case & $\begin{array}{l}\text { Radius } \\
\text { Tratectory }\end{array}$ & $\begin{array}{c}\text { Alpha-Particle } \\
\text { Energy } \\
\text { Distribution }\end{array}$ & $\begin{array}{c}\text { Alpha-Particle } \\
\text { Yas } \\
\text { D1gtribution }\end{array}$ & $\begin{array}{l}\text { Energy } \\
\text { Transport }\end{array}$ & $\begin{array}{c}\text { Burn time } \\
\underline{I}_{B}(b)\end{array}$ \\
\hline$A^{(a)}$ & noving & $n^{2}$ & $\mathrm{n}^{2}$ & $200 \tau_{\mathrm{BO}} \mathrm{KA \textrm {A }}$ & 21.6 \\
\hline B & fixed & $n^{2}$ & $n^{2}$ & $200 \tau_{\mathrm{B} J \mathrm{HM}}$ & 25 \\
\hline C & fixed & $\mathrm{n}^{2}$ & $n^{2}$ & $\begin{array}{l}200 \tau_{30 \mathrm{HM}} \\
\text { plue Suydam } \\
\text { turbulence }\end{array}$ & 25 \\
\hline D & $\begin{array}{l}\text { moving/fixed } \\
\text { (optimized) }\end{array}$ & $\mathbf{n}$ & $\mathbf{n}$ & $200 \tau_{\mathrm{BOHM}}$ & 21.6 \\
\hline $\mathbf{E}$ & fixed & n & $\mathbf{n}$ & $200 \tau_{B O H M}$ & 25 \\
\hline$F$ & fixed & $\mathrm{n}^{2}$ & $\mathbf{n}$ & $200 \tau_{\mathrm{BOHM}}$ & 25 \\
\hline
\end{tabular}

(a) closest simulation of zero-dimensional model

(b) quench time taken as 58

and toroldal field profiles within the plasma region were modeled by approprlate Bessel functions

$$
\begin{aligned}
& n(r, 0)=n(0,0) J_{0}^{2}(0.94 \alpha r) \\
& B_{\phi}(r, 0)=B_{\phi}(0,0) J_{0}(\alpha r),
\end{aligned}
$$

where $\alpha=2.405 / r_{p}(0)$. Using the above initial conditions, the Initial pololdal field profile is computed to satisfy pressure balance.

Figure 5 compares the averaged Ion and electron temperatures obtained with the one-dimensional model for Case $A$ with the predictions of the zero-dimensional model. Shown also is the time dependence of the peak pololdal beta aid the fractional buruup of DT fuel. The radial dependenca of temperatures and fields 12-8 into the 1gnited burn is depicted in F18. 6. In adition to illustrating the radial density profile at $12 \mathrm{~s}$, F18. 7 gives the 18 adlat dependence of the ohear paraweter, $P=1 / \dot{v}$, and the Suydam parameter, 

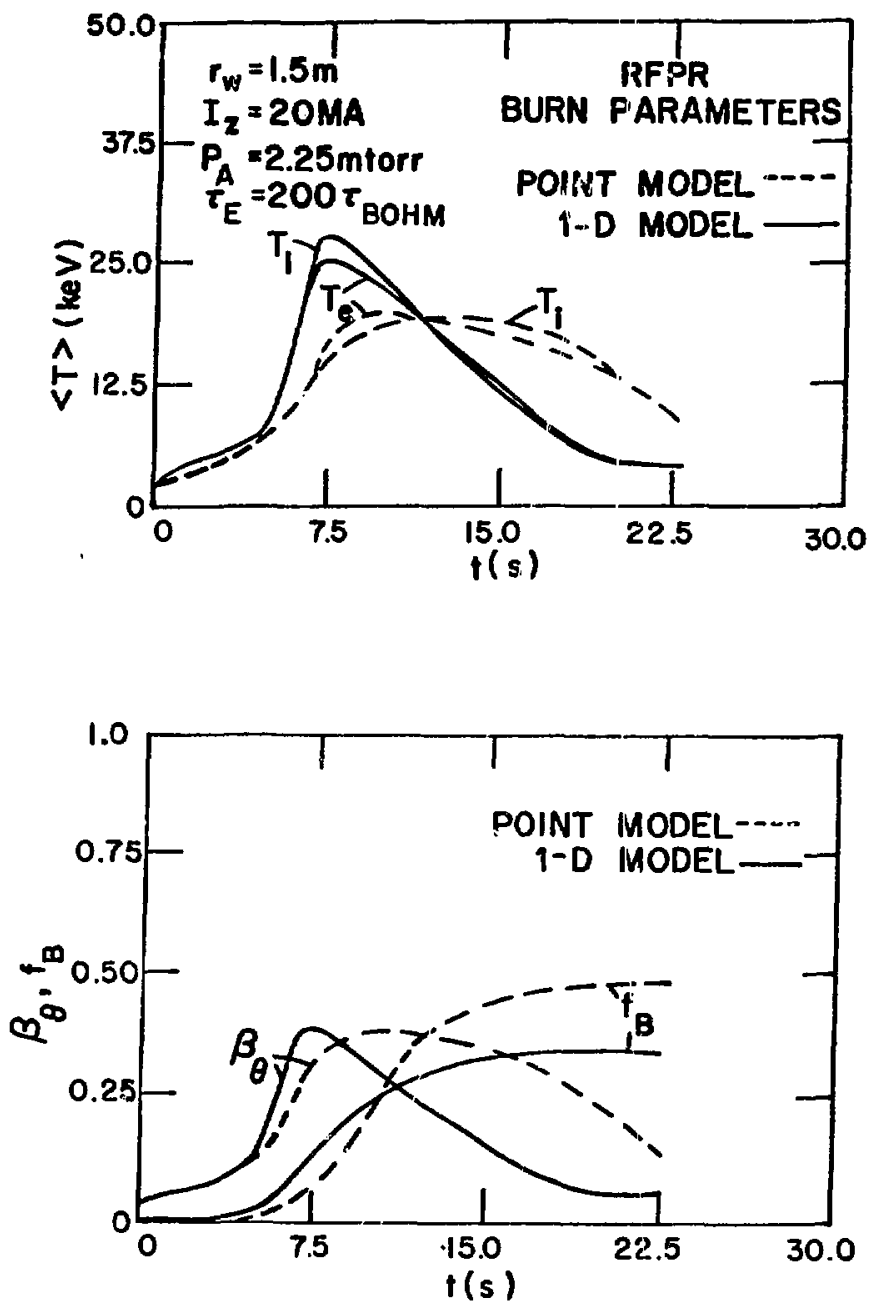

F1g. 5 .

Comparison of averaged parameters versus time as predicted by the Case A one-dimensional simulation and the zero-dimensional model.

$f_{8}(\mathrm{Eq} \cdot(14))$. It 18 noted that for the parameters shown, $f_{8}>0_{5}$ and the plasma is unstable to local Suydam modes over Its entire volume. Lastly, F1g. 8 compares the neutron, transport, and radiation energy flux at the firat wall for the Csse A simulation.

The differences between the point and one-dimensional models 11luatrated in Figs. 5-8 can be attributed to differences in assumptions. First, the point model assumes a uniform plasma temperature, where the radially varying temperatures and associated enhanced fusion reactivity (and alphe-particle heating) In the central plasma region results in a higher average teaparature 

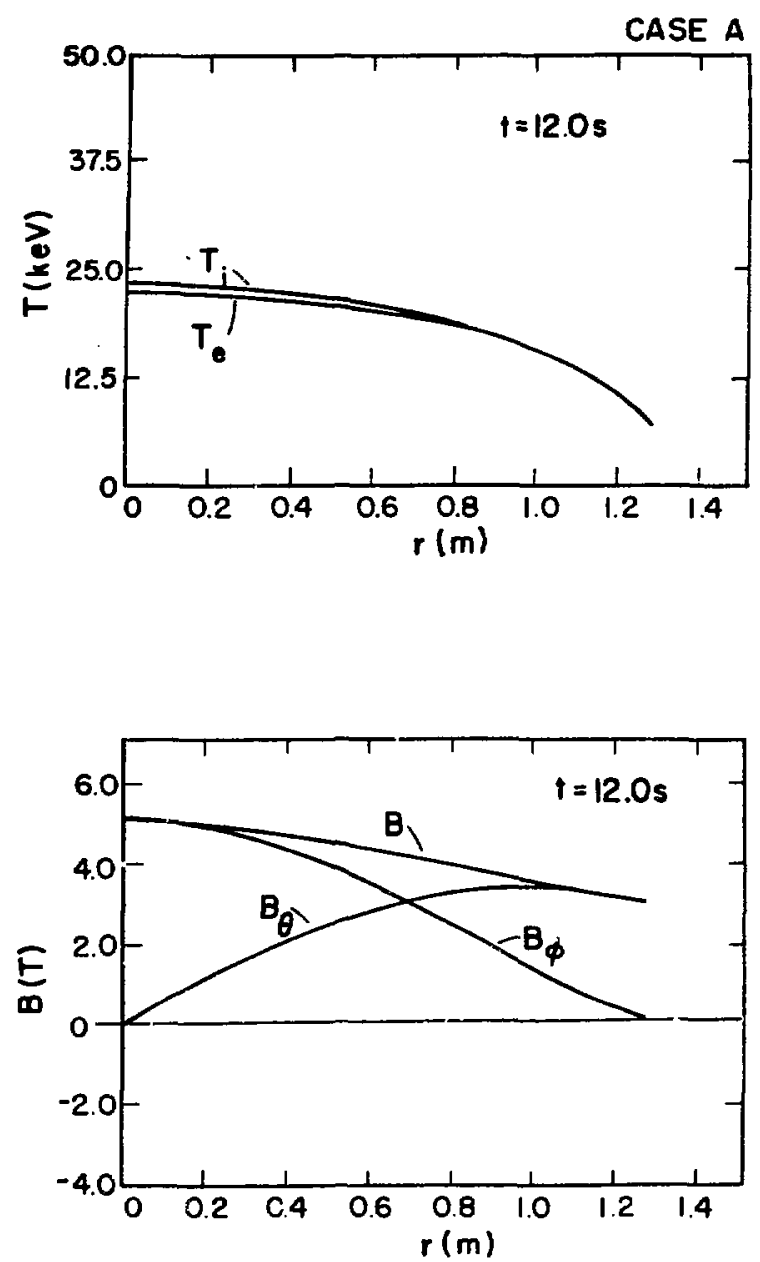

F1g. 6.

Temperature and field profiles for the Case A simulation at $12.0 \mathrm{~s}$ Into the burn phase.

shortly after Ignition (Fig. 5): Consequently, the one-dimensional model burns out more rapidly, resulting in a lower value for $f_{B}$ (FIg. 5). This lower fuel burnup (batch or unrefueled burn 18 assumed for both models) can be attributed to differences in alpha-particle heating and fuel density profiles as the burn evolves.

It 18 noted that the point model assumes that the alpha-particle energy deposition occurs uniformly across the plasma radius and that the fuel density mafntains 1 ts Initially specifled radial profile (Eq. (16)). The one-dimensional model assumes in eltu alpha-particle heating and fuel burnup, 

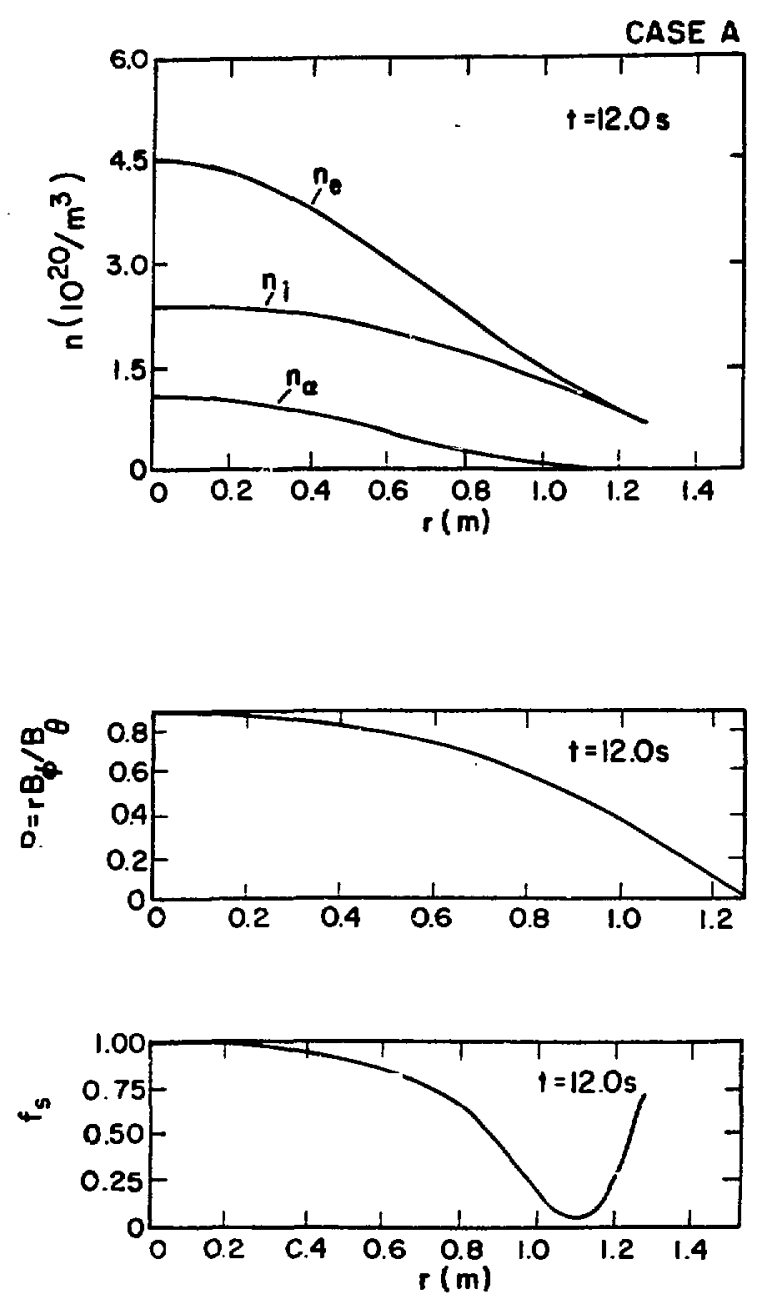

Fig. 7.

Profiles of density, pitch parameter, $P$, and Suydam parameter, $f_{8}$, for the Case A simulation at 12.0 s into the burn phase.

resulting in a comparatively higher alpha-particle bulldup and subsequently lower fuel fraction in the central region of the plasma. Since a major portion of the fusion reactions occur in this hotter, more dense central region, the one-dimensional simulation burns out more rapidiy with a resulting total fuel burnup fraction that is lower.

The point burn model must specify a magnetic fleld profile to assure pressure balance and cannot account for resistive decay of the toroidal field $B_{\phi}$. In forcing a radius trajectory, $r_{p}(t)$, the one-dimensional model wat force the toroldal current, $I_{\phi}$, to decay, as resistive $1088 e$ consune $B_{\phi}$ 




Fig - 8.

Comparison of first-wall neutron. thermal conduction, and radiation fluxes for the Case $A$ one-dimensional simulation and the zero-dimensional model.

field. This artifact results in somawhat less ohmic heating, although this effect is small.

The radial profiles shown In F1gs. 6 and 7 remain relatively unchanged throughout the burn period. Unlike earlier simulations, ${ }^{4}$ both the temperature and pressure show a maximum on the plasma centerline because of the assumed Bohn-like thermal conductioa. The fact that the bulk plasma is unstable to Suydan modes, however, must be reflected In an enhanced transport, the inplications of which is examined by Case C. Table $V$ summarizes cructal performance parameters for both the zero-dimensional and Case $A$ one-dimensional simulations. Of particular interest is the plasma Q-value, $Q_{p}$, defined in Table $v$ as the ratio of total fusion yleld, $1.25 \% \mathrm{~N}$, to the sum of the total obric dissipetion, WOHM, and the fleld energy stored in the plasen. WBf, at the end of the burn phase but before plasma current rundown and quench: It is seen that for the conditions under which Case $A$ was 
SUMMARY COMPARISON OF ENERGY BALANCE FOR ZERO-AND ONE-DIMENSIONAL BURA MODELS PARAMETER (MJ/m) ZERO-D ONE-D ${ }^{\mp}$ ONB-D ${ }^{8}$ ONE-D ${ }^{\text {h }} \quad$ ONE-D $^{1}$ CASE A CASE B CASE C CASE D

Burn time $\tau_{B}(s)$

Initial plasma energy,

$\mathrm{w}_{\mathrm{p} 1}$

Final piasma energy,

$W_{p f}$

Rad Lation energy ${ }^{a}$.

WRAD

Ohmic heating energy,

WOHM

Plasma energy 1088

(conduction), $W_{\text {COND }}$

Plasma expansion

er.ergy, WPV

Eddy current losses in

the blanket/shield,

$W_{\text {EDDY }}$

Magnetic-field energy

Inside first wall

at end of burn

cycle, $W_{B f}$

Magnetic-fleld energy

transfer losses, WETS

Fusion Neutron Pnergy,

$\mathrm{W}_{\mathrm{N}}(14.1 \mathrm{MeV})$

Auxtllary energy re-

quirements, $W_{\text {AUX }}$

$Q_{p}=$ (fuston energy)/

(ohmic + fleld energy)

21.6

21.6

24.6

25.0

0.8

0.8

22.

$\begin{array}{lllll}0.05 & 0.7 & 0.8 & 0.8 & .99\end{array}$

2.5

1.9

3.0

3.1

3.68

28.1

14.3

14.8

13.9

19.3

\section{1}

8.9

10.4

12.4

8.93

$147.5^{b}$

93.0

115.2

114.5

146.7

0.7

1.1

0.0

0.0

0.0

1.5

$51 \cdot 6^{c}$

45.0

45.1

45.5

30.6

$$
8.1^{\text {d }}
$$

676.5

410.

493.5

469.7

646.2

$14 \cdot 3^{e}$

14.4

9.5

11.1

10.1
20.4

aBremsstrahlung and Ine radiation

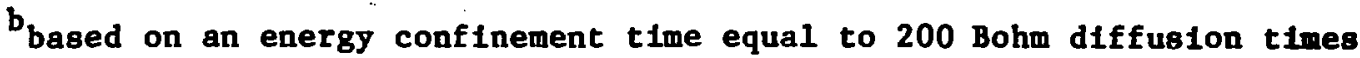

ca significant fraction of this energy would be recovered during plana current rundown and quench ( 50\% recovered in RFPR reactor design)

dbased on a $95 \%$ efficlent Inductive/capacitive transfer fron the homopolar motor/generator (capacltive) to and from the magnets

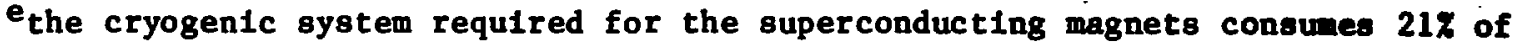
the auxiltary power

fradius forced to follow zero-dimensional case

Bfixed plasma radius; Bohm conduction

$h_{\text {flxed plasma radius, Suydam turbulence }}$

$1_{\text {fixed plasma radius, Bohm conduction }}$ 
evaluated, a factor of $\sim 1.5$ decrease in $Q_{p}$ relative to the point model is predicted. This significant difference in $Q_{p}$ 1llustrates the net Influence of profile effects, with the reduction in $Q_{p}$ a direct result of the lower fuston yield because of differences in the evolution of the fuel density profile during the burn, as previously discussed. As for any model, these differences in predicted $Q_{p}$ values are sensitive to modelistic assumptions. Some of these assumptions are examined further.

B. Comparison of Constant Radius Cases With and Without Enhanced Transport, Cases B and C.

The one-dimensional model was evnluated for a programmed rather than a constant toroldal current, using the formalism for suydam turbulent transport represented by Eqs. (13) and (14). A comparison for the constant radius case with and without Suydam turbulence 18 presented in Fig. 9, where the time dependence of average temperature, $B_{\theta}$, and $f_{B} 18$ given. The radial profiles of temperatures and flelds with and without Suydam turbulence are depicted in Fig. 10, whereas Fig. 11 gives the radial dependence of densities, pitch parameter, $P$, and Suydam parameter, $f_{8}$. Key plasma parameters for Cases $B$ and $C$ are also summarized on Table $V$.

Even without Suydam turbulence enforced a greater fraction of the plasma volume becomes Suydam stable (F1g. 11) for tìe constant-radius Case B. Simulation of Suydam turbulence by causing anomalous Bohm-like transport to occur In Suydam unstable reglons (Eqs. (13) and (14)) flattens the density profiles in the center of the plasma, causing a similar leveling of the pressure profile and pushing the plasma towards the marginal Suydam stability region.

Compartson of the Suydam stability parameter, $f_{8}$, for Cases $B$ and $C$ shows that enhanced anomalous transport transforns the plasma from one of untform Suydam Instability to a pointwise, stochastic violation of the suydam criterion. As an unstable plasma region is stabilized by anomalous transport, pressure gradients in adjacent regions are increased, causing these latter regions to become unstable. The net result 1.8 a randomized or statistical violation of the Suydam criterion in regions of weak shear and an enhanced transport. These computational results indicate that, 1ike the tokamak, a najor contribution to the plasma confinement is provided by the plasma edge reglons. 

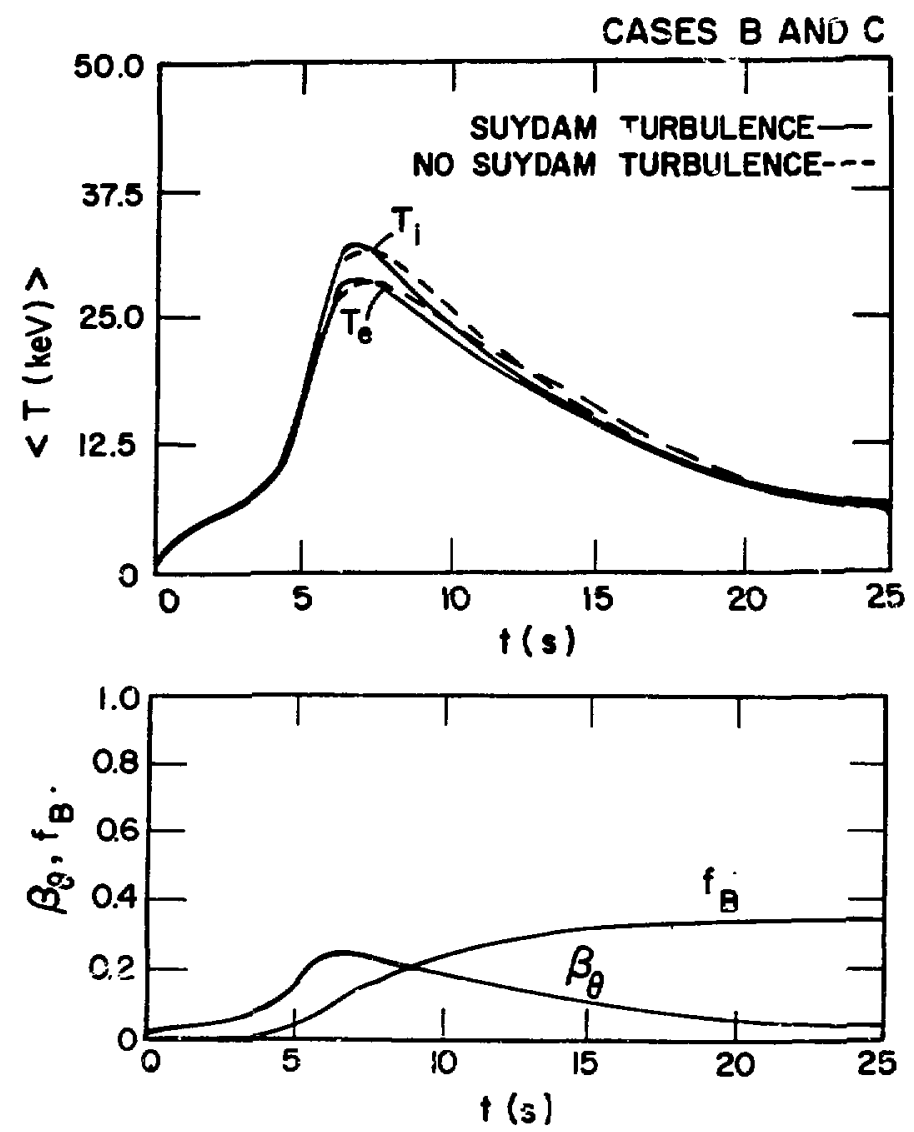

F1g - 9.

Comparison of Case $B$ and Case C one-dimensional simulations showing the Influence of Suydam turbulence on the average temperatures; polotdal beta, and burnup fraction. For $f_{B}$ and $\beta_{\theta}$, no difference was observed.

The magnetic flelds maintain a continuous topological structure despite the enhanced transport asscelated with the Case $C$ conditions. Perturbations In both fleld and pitch parameter proflies are small compared, to density perturbations (FIg. 11). This result 18 caused by scaling the anomalous transport through the perpendicular resistivity, $\eta_{\perp}$ (Eqs. (13) and (14)), rather than through both perpendicular and parallel. components; this method implicitly assumes that turbulence results in enhanced transport directly, rather than by only increasing collisionality.

Despite the significant differences in transport models used in Cases B and $C$, the plasma Q-value is Increased only $\sim 20 \%$ from the Case A comparinon case; a factor of 1.3 then separates the predictions of the one-dinensional 



Fig. 10.

Comparison of Case B (no turbulence) and Case C (with turbulence) one-dimensionel simulations in terms of temperature and field profiles that have evolved at $\sim 10$ s into the burn.

and zero-dimensional models. If Case $B$ is re-evaluated with alpha-particle deposition proportional to ion density, $Q_{p}$ increases slightly from 11.1 to 11.6. The reasons for this depressed Q-value are assoclated with the premature burnout of the plasma central core, the lower fuel burnup and a diminished thermonuclear yleld. Increasing the burn time results in narginally Iuproved Q-values. If Case B is simulated with $40 \%$ increase In filling pressure, $Q_{p}$ Increases from 11.1 to 17.4, however. Both thermal and neutron first-wall flux IImits will eventually Intervene as the Q-value Is 26 
CASE B
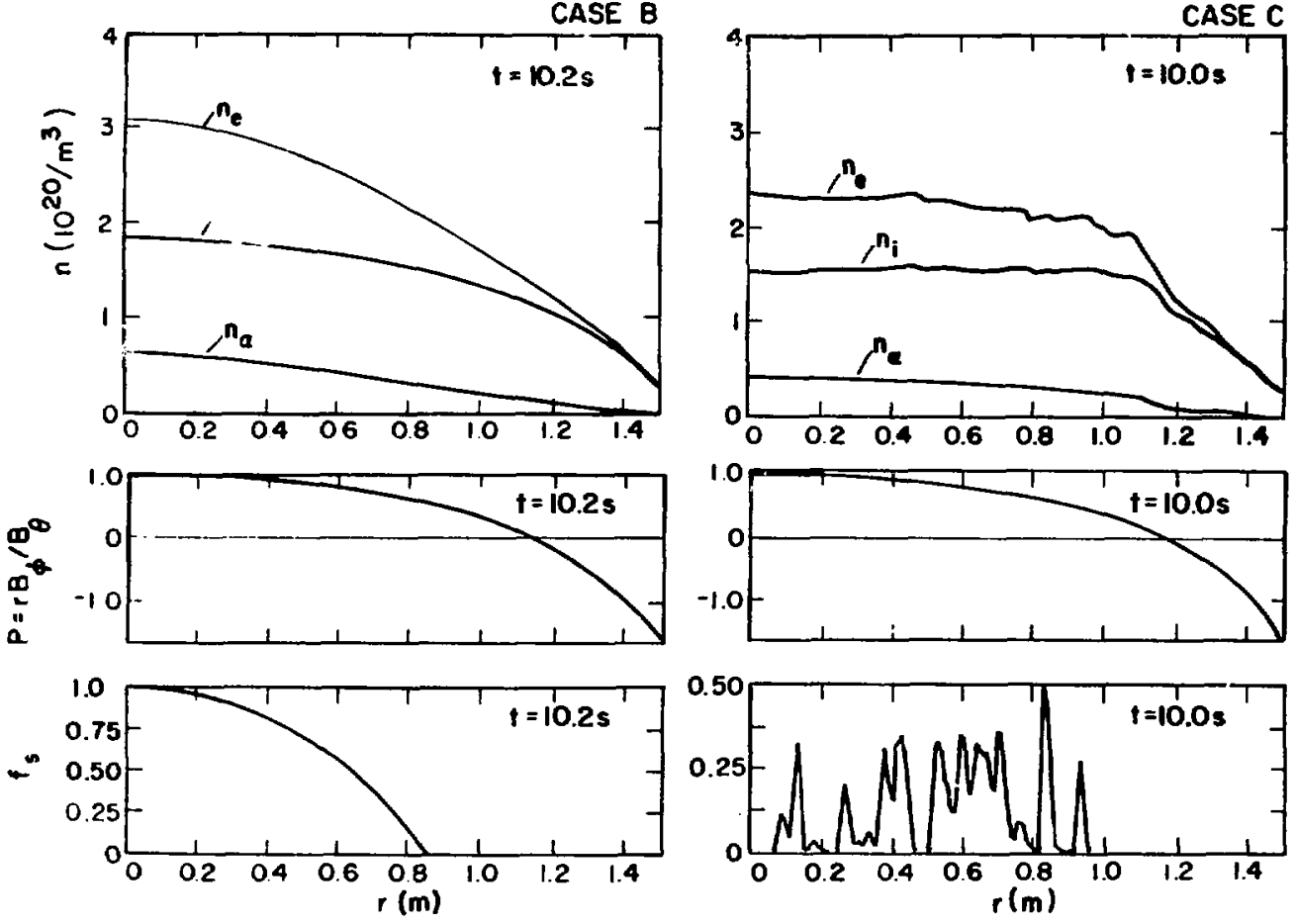

F1g. 11 .

Comparison of Case $B$ (no turbulence) and Case $C$ (with turbulence) one-dimensional simulations in terms of density, $P$, and $f_{s}$ profiles that have evolved at 10 s into the burn phase.

increased by ralsing the plasma density and correspondingly the plasma beta. This issue is addressed quantitatively in the following section.

C. Parametric Studies Leading to Potentlally New RPPR Operating Points.

In order to amellorate the adverse effects on the plasma Q-value associated with central core burnout the effects of both a number of alternative alpha-particle thermalization models and variations in plasma density and magnetic fleld levels were examined. The resulting sensitivity of $Q_{P}$ to these assumptions is summarized. For all cases, particle transport per se was treated only within the classical Lagrangian framework, as described in Sec. III. A. Anowalots particle transport could possibly permit a larger burnup fraction and $Q_{p}$ for a batch-burn operating mode; this question is also 
addressed briefly. Some form of refueling may be required in order to retrieve the favorable $f_{B}$ and $q_{p}$ values predicted by the zero-dimensional model and used as a basis to estimate the RFLR engineering parameters, 1 although modest change in the toroldal magentic fields are shown to also lead to increased $Q$ values.

1. Dependence of $Q_{p}$ on Plasma Density and Al.pha-Particle Models

As Indicated in Sec. IV. B and Table V, the mechanism by which alpha-particle energy and mass is distributed over the plasma radius has a minor influence on the plasma Q-value. Figure 12 quantifies this effect, wherein the dependence of $Q_{p}$ on line density is shown for a range of alpha-particle thermalization models (Table IV). Figure 12 also illustrates the dependence of the 14.1-MeV first-wall loading on line density. Setting $\sim 4-5 \mathrm{MW} / \mathrm{m}^{2}$ as an upper limft on the neutron wall loading, values of $Q_{p}$ in the range 15-20 are expected, which is significantly greater than the value (14.4) used for the point-plasma RFPR design. I General trends and observations not reflected by $\mathrm{Fig} \cdot 12$ are:

- The higher density cases generally tend to burn out faster than the lower density cases. This behavior would result in a higher instantaneous neutron and thermal loading at the first wall for a fixed quench period of $T_{Q}=5$.

- The models that allow the plasma radius (1.e., the reversal point) to move in some cases predicted the plasma radius contacts the fixed wall radius $(\mathrm{rW}=1.5 \mathrm{~m})$.

- The higher density cases generally achleved higher plasma temperatures.

- Cases $A$ and $D$ at a Iine density above $4.5(10)^{21} \mathrm{~m}^{-1}$ did not ignite.

2. Optimization of RPPR Design Point by the One-Dimensional Model

The re-optimization of the RFPR design point by the one-dimensional model 18 the primary motivation for this study. Overall reactor syatem considerations are not within the scope of this work, and a comparison with the point model is used to gauge whether or not the predictions of the one-dimensional model are favorable or not. Establishing a 14.1-HeV neutron wa11 loading near the reference design ${ }^{l}\left(2.7 \mathrm{MW} / \mathrm{m}^{2}\right)$, while maintaining a 




Fig. 12.

Dependence of plasma Q-value, $Q$, and 14.1 -HeV neutron wall loading on line density and alpha-particle models for the five cases summarized in Table IV.

similar power output, fixes the plasma line density at $1.5(10)^{21} \mathrm{~m}^{-1}$. Using Case D (with fixed radius) 11sted In Table IV, the magnetic field levels were adjusted until the $Q$-value reached a maximum. A plot of $Q_{p}$ versus $B$ os the Initial blas magnetic fleld on axis, 18 shown In FIg. 13 and 11 lustrates that the Q-values Increase as $B_{\text {po }}$ decrease because of the reduced quantity of 


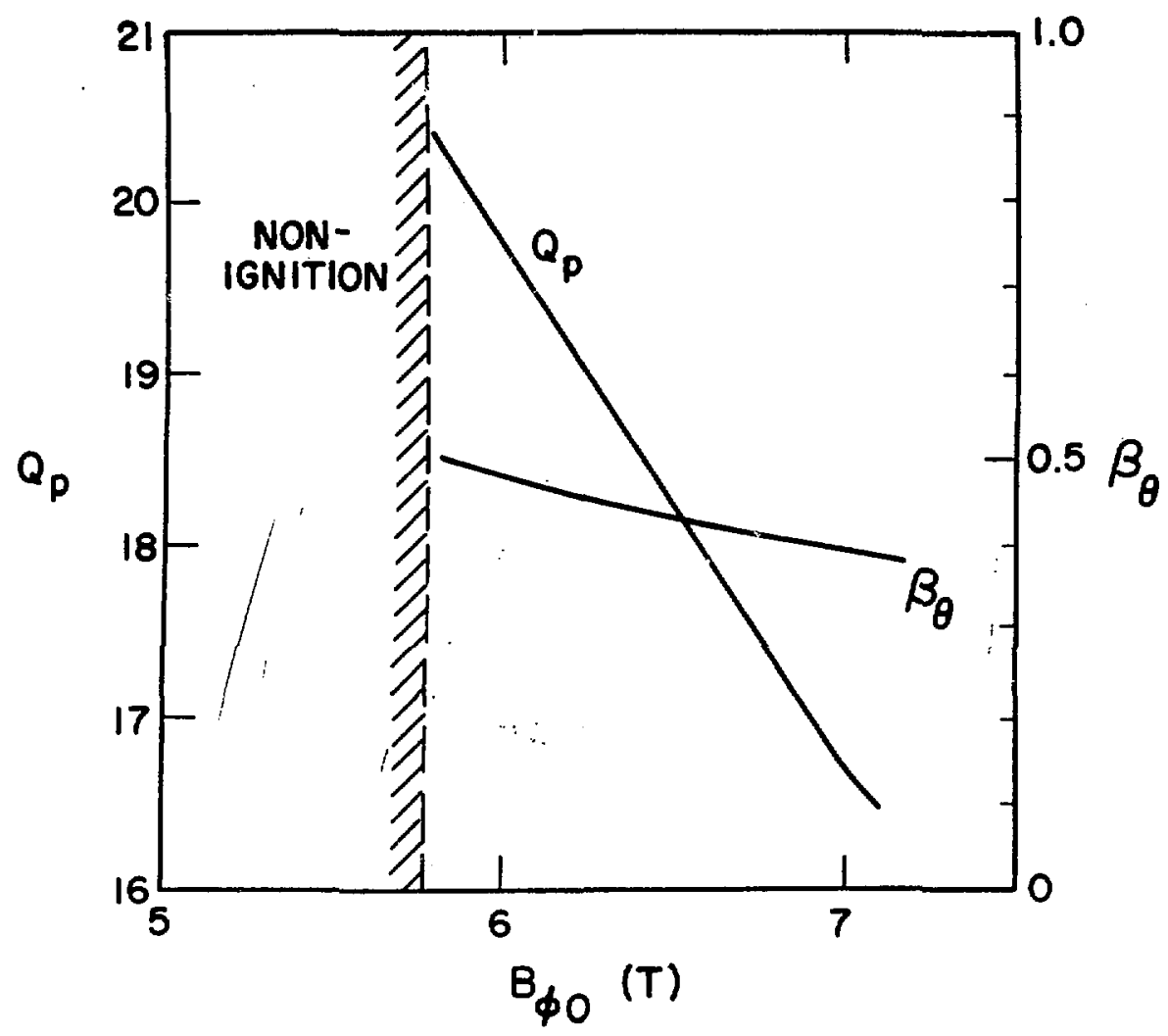

Fig. 13.

Dependence of plasma Q-value and associated maximum poloidal beta on the initial toroidal bias field.

magnetic field remaining in the plasma at the end of the burn. If $B$ po is reduced below $\sim 5.8 \mathrm{~T}$, plasma ignition does not occur. A tabular comparison between the optimized point-model calculation and the one-dimensional optimized calculation 18 shown in Table V as Case D. As noted in Fig. 13, the poloidal beta increases from 0.39 to 0.51 as the magnetic flelds are reduced; although high, this beta still remaining within stability limits as predicted by Ideal MHD theory. If lower beta limits are enforced, the overall RFPR efficlency decreases somewhat, although detalled parametric studies ${ }^{1}$ show that the attendant decrease in system performance (and cost) does not become serious until the maximum allowable $\beta_{\Theta}$ falls below 0.15 .

- The tIme dependent electron and $10 n$ temperatures for the $Q_{p}=20.4$ case show In FIg - 13 are plotted in Fig . 14, along with the fractional burnup, $f_{B}$, and polotdal beta, ${ }^{B}$, which peaks at 0.5 . The plasma power response is also given in $\mathrm{Fig}_{\mathrm{g}} 14 \mathrm{with}$ the total integrated output being within $5 \mathrm{z}$ of that used 

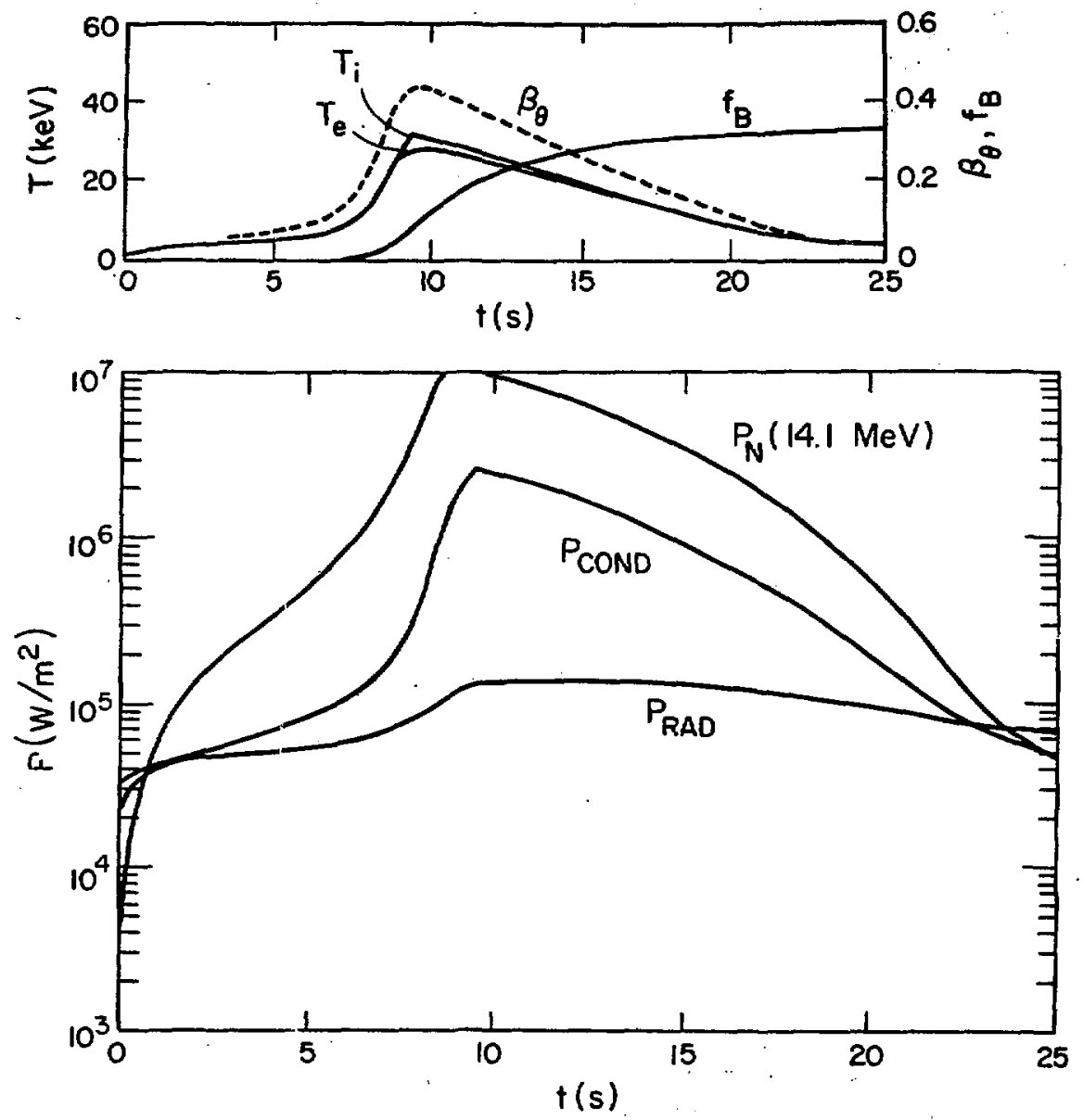

F18 - 14.

Time dependence of average plasma temperatures, beta, and DT fuel burnup fraction for the optimum design point. Also shown are the neutron, radiation and conduction powers expressed per unit first-wall area.

in the RFPR reactor design. 1 The radial dependence of the magnetic. fielde is shown in FIg. 15 for $t=0,10,20$ s. At $t=0$ the plasin preseure is 



Fig. 15.

Radial profiles of the magnetic flelds, particle densities, ion and electron temperatures, magnetic field pitch and the Suydam stability parameter $\left(f_{s}\right)$ for the optimal design point at various times.

essentially zero, and the magnetic field profiles describe a pressureless plasma state. Plasma expansion occurs as the plasma heats, and the magnetic fields near the center necessarily drop in order to maintain pressure balance. This behavior is 11lustrated in Fig. 15 by the curves for $t=10-8$. Near the end of the burn $(t \simeq 20 \mathrm{~s})$ the plasma 18 again cool, and the flelds again relax toward the center, although resistive dissipation tends to flatten the profiles. The effect of plasma expansion 18 also exhibited by the electron density profiles depicted in Fig - 15. Once again, a general flattening of the profiles (In this case the electron density) results during the $20-8$ burn 
cycle. The effects of fuel burnup ăre 11lustrated in Fig. 15 by the decreasing ion density and corresponding increase in alpha-particle density as the burn proceeds. Finally, the pitch of the magnetic fields versus radius is shown in Fig. 15 along with a graphic illustration of the regions of Suydan stability violation. Only a small region of the pinch is inftially unstable to this pressure dependent instability, which tends to grow as the plasma temperature is increased. At $t=10 \mathrm{~s}$ the plasma temperature is nearly maximum, and the largest area of Suydam violation orcurs. This area of Suydam instability is reduced as the plasma temperature de;reases near the end of the burn, although relaxation of the profiles also has contributed to the degradation of the stabilfty. The existence of a turbulent Suydam-unstable central region is common to axisymmetric configurations of this type (both the tokamaks and the RFP) and is not expected to IImft severely the confinement properties because of the stable buffer region that exists between the turbulent plasma core and first wall. This behavior was in fact shown numerically by this study (Sec. III.D) in which the inducement of turbulence and enhanced transport in regions of Suydam violation did not produce significantly different plasma performance. The transport loss corresponding to $200 \tau_{B O H M}$ dominates any other Induced $108 s e s$ required to force the profiles into a nearly Suydam-stable configuration.

\section{CONCLUSIONS}

Agreement is good between the zero-dimensional and one-dimensional RFPR burn models. This agreement gives more confidence in the RFPR design point reported earlier ${ }^{l}$ on the basis of a zero-dimensional analysis. The minor differences that have emerged $t$ tween the two models can be attributed primarily to profile effects. In a sense, this agreement between the one-dimensional and zero-dimenstonal models is fortuitous in that both models are based on similar physics assumptions; a number of these assumptions remain to be validated or disproved by experiment. The one-dimensional model, however, represents an important tool by which the sensitivity of RFPR performance to important physics assumptions can be parametrically evaluated. Given below is a synopsis of key conclusions that have been drawn from this comparison study. 
- The one-dimensional model Indicates the Importance of local 1gnition and fuel burn-out. Although the observed center-line burnout causes some nodification of the burn trajectory, as estimated from the zero-dimensional model, the overall plasma performance, remains essentially unaltered.

- The plasma performance appears to be relatively insensitive to the alpha-particle thermalization and transport model, provided a major fraction of the total alpha-particle energy is delivered to the plasma.

- The one-dimensional model shows that a substantial portion of the plasma is unstable to local Suydam modes. Attempts to Induce an enhanced or turbulent transport assoclated with this local instability had little effect on the overall plasma performance. The Suydam-induced transport causes a stochastic varlation in the local violations of the Suydam criterion, and this transport was induced through the perpendicular electrical resistivity. The resistivity related transport was small compared to the consistently assumed $\sim 200 \tau_{\mathrm{BOHM}}$ enhanced thermal conductivity.

- The global stability tests Indicates good stability against gross m $=0,1$ modes for all cases examined.

- The zero-dimensional model tends to over estimate the plasma current required to Ignite the plasma. The one-dimensional model, on the other hand, allows a local ignition to occur at the plasma center Iine. This local Ignition rapldly propagates radlally outward. Consequently, the one-dimensional Ignition can occur at lower flelds, and Improved values of $Q_{p}$ would be predicted by the one-dimensional simulations.

- Differences in the plasma Q-values, $Q_{p}$, arise between the fixed versus the vartable radius cases. An increasing plasma radius results in an increased beta ( ${ }^{2}$ decreases faster than the plasma pressure as the radius increases). For a fixed (given) beta limft, therefore, constant radius operation yields a higher Q-value. This mode of operation, however, may complicate the reactor operation somewhat because the plasma currents must be more carefully controlied to achleve a constiant radius operation.

- The ose-dimensional burn model has led to an Improved reactor design point that 18 characterized by greater latitude and flexibility in achieving a given performance level.

- The fundamental conclusion that the RFPR can operate efficiently and economically in the considerably simpler. batch-burn (unreiueled) mode remains unchanged if not firmer.

- The largest uncertainty assoclated with the RFPR prognosis rests with the assumed physics of particle/energy transport; this uncertainty can not be resolved by code development at any level-of-effort, although careful parametric studies can at least establish limits for this uncertalnty.

- The one-dinensional rodel has been developed and tested against the global, zero-dimensional model, rendering more confidence in each, within the uncertainties of the physics assumptions. The more elaborate and flextble one-dimenatonal nodel can now be used to examine effects and parameter 
varlations heretofore unaccessible by the zero-dimensional model. For example:

- alpha-particle thermalization, transport, orblt effects, 1osses, etc.

- Impurity transport

- better evaluation of models that couple particle/energy/field transport and the local state of MHD stability

- model RFPR startup (low-beta, fleld reversal) and shutdown (field energy recovery, plasma cooling) processes

- model refueling and ash-removal schemes that would be required for sustained thermonuclear burns

\section{ACKNOWLEDGMENTS}

The advise and guidance of Professor George $H$. Miley of the University of Illinots is gratefully acknowledged.

\section{REFERENCES}

1. R. L. Hagenson, R. A. Krakowski, and G. E. Cort, "The Reversed-Field PInch Reactor", Los Alamos Sclentific Laboratory report LA-7973-MS (August, 1979).

2. J. B. Taylor, "Relaxation of Toroidal Discharges," Third Topical Conference on Pulsed High Beta Plasmas, p. 59, Culham, United Kingdom, (1975).

3. D. Montgomery, L. Turner, and G. Vahala, "Three Dimensional Magnetohydrodynamic Turbulence In Cylindrical Geometry," Phys. Fluids, 21, 757-764 (1978).

4. R. A. Nebel, G. H. Miley, and R. W. Moses, "Reversed-Field P1nch Burn Dynamic8," IEEE Intern. Conf. on Plasma Science, Montreal, p. 196 (1979).

5. R. L. Hagenson and R. A. Krakowski, "A Cost-Constrained Design Polnt for the Reversed-Field Pinch Reactor," Proc. Am. Nucl. Soc. Third Topical Meeting on the Tech. of Cont. Nucl. Fusion, 1, 90-100, Santa Fe, M, (1978).

6. B. R. Suydam, "Stability of a Linear Pinch," Proc. 2nd UN Inter. Conf. on the Peaceful Uses of Atomlc Energy, 31, 157-159, Geneva, Sw1tzerland (1958).

7. W. A. Newcomb; "Hydromagnetic Stability of a Diffuse Linear Pinch", Annals of Physics, 10, 232-267 (1960). 
8. D. C. Robinson, "H1gh- $\beta$ Diffuse Pinch Configurations", Plasma Physics, 13, 434-462 (1971).

9. J. P. Christiansen and K. V. Roberts, "Evolution of the Reversed-Field PInch", Muc1. Fuston, 18, 2, 181-197 (1978). 